\title{
COLLABORATIVE INTELLIGENCE - DEFINITION AND MEASURED IMPACTS ON INTERNETWORKED E-WORK
}

\author{
Hao Zhong, Rodrigo Reyes Levalle, Mohsen Moghaddam, Shimon Y. Nof \\ PRISM Center \& School of IE, Purdue University, West Lafayette, USA
}

Corresponding author:

Mohsen Moghaddam

School of Industrial Engineering

315 N. Grant St.

West Lafayette, IN 47907-2023, USA

phone: (+1765) 494-54-27

e-mail: mmoghadd@purdue.edu

Received: 27 October 2014

Accepted: 23 December 2014

\begin{abstract}
Internetworked e-Work is enabling new channels in cyber space for collaboration among physical and cyber agents, e.g., humans, robots, software agents. Research on Collaborative Control Theory (CCT) indicates that building and augmenting the Collaborative Intelligence (CI) of participants in cyber-physical networks can provide better support for achieving their individual and common goals. In spite of its rising significance and popularity, however, no clear and precise definition and universal quantitative measure has been proposed for the CI. In this article, we first formalize the CI by suggesting a formal definition, based on the definitions of its elements - collaboration and intelligence. We then propose a quantitative measure for the CI, adapted from the universal intelligence measure. For illustration, we analyze three recent collaborative e-Work studies at three different scales: (1) Telerobotenabled computer supported collaborative design; (2) Collaborative product line control in supply networks; (3) Demand and capacity sharing in multi-enterprise collaboration. From these case studies, common advantages such as work efficiency, network robustness and stability, service level, resource utilization, and collaboration cost are observed, analyzed, and translated into formal CI measures. Results indicate significant impacts of CI on the efficiency, effectiveness, and quality of collaborative activities in emerging e-Work networks.

KEYWORDS

collaboration lifecycle management, computer-supported collaborative work, enterprise collaboration, intelligent control, resilience, collaborative control theory.
\end{abstract}

\section{Introduction}

Collaboration is a pervasive need of human civilization. It enables powerful augmentation of systems to sustain and evolve. This augmentation includes any natural or artificial system, from genomes, multicellular organisms, social insects, and human societies to the networks of sensors, computers, robots, and factories $[1,2]$. Collaboration is enabled through sharing information, resources, and responsibilities by distributed agents to jointly plan, implement, and analyze the activities required to achieve individual and common goals [3].

Since the invention of the Internet, we have gained a new capability of communicating and in- teracting with peers and with knowledge repositories remotely, through cyber connections [4]. Internetworked e-Work is a culmination of many collaborative activities based on information technology [3]. Examples of such collaborative activities include [5]:

1. Humans use a variety of web applications for remote communication and knowledge sharing.

2. Functional groups of an organization establish supply networks of knowledge and goods via Internet-based technologies.

3. Organizations are increasingly transforming into highly distributed, internetworked Small-andMedium Enterprises (SMEs), which divide technologies, tasks, and responsibilities to sustain and succeed. 
Nevertheless, blind collaboration, by itself, does not guarantee successful achievement of the targeted criteria, e.g., efficiency, responsiveness, agility, scalability, and so forth. What makes a difference is intelligent collaboration. Collaboration without effective knowledge exchange and transfer for shared insight fostering is the root for errors, conflicts, and failures. In this context, we define Collaborative Intelligence (CI) as a measure to calculate the collaborability (collaboration-ability) of agents in addressing the following challenges [6, 7]: How to define and identify the best collaborators? When and why to collaborate with other agent(s)? What resources to share? What collaborative network structure to use? How to handle and prevent potential failures?

Intelligence has different definitions and implications in various kinds of interaction mechanisms; from communication mechanisms [8] to knowledge accumulation [9], cooperation [10], integration [11], and collaboration [12]. Regardless of the level and complexity of such mechanisms, however, they all refer to certain abilities (of the system and/or its components) to deal with the intended objectives of their interactions [7]. However, there is no clear and precise definition and universal quantitative measure for the intelligence in interactive mechanisms, in general, and for the CI, in particular. This lack of formalism may in turn hinder the theoretical and practical investigations on the design of intelligent collaborative systems.

Based on this motivation, this article provides a formal definition along with a quantitative measure for the CI. We approach this problem by separately analyzing the formal definitions of each of the two elements of the CI, i.e., collaboration and intelligence. Then, we unify these two concepts and come up with a definition and a generic mathematical formula for measuring the CI (Sec. 2). We conclude our work by presenting three cases of collaboration in internetworked networks at different scales, illustrating how the CI can be defined and measured in each case (Sec. 3). At the end, we provide a summary along with some guidelines for further enhancement of the CI in internetworked e-Work systems through theories, models, and frameworks for engineering augmentation of collaboration (Sec. 4).

\section{CI - Definition \& Measure}

The preliminary step towards constructing a generic, precise, and quantifiable definition for the CI is to do the same for each of its elements, i.e., collaboration and intelligence. We address this issue in this section by first defining each concept and re- viewing various terminologies, definitions, and their relationships, in the scope of e-Work. Then, we unify these two concepts to develop a formal definition and quantitative measure for the CI.

\section{Collaboration}

Collaboration is one of the basic principles for sustainability and evolution of any organization of natural or artificial entities, including cyber, physical, and cyber-physical systems [1]. Various definitions have been proposed for the term collaboration. Oxford dictionary defines collaboration as "the action of working with someone to produce or create something". For instance, humans work with machines (e.g., driver-car; pilot-aircraft), e-Business parties work with each other (e.g., clients-servers; buyers-sellers), all to create benefits that are/may not be achievable individually. That is, some activities necessitate collaboration among the entities (known as mandatory collaboration), while some other activities do not necessarily rely on, but can be improved by collaboration (known as optional collaboration). Besides, collaboration does not always take place among peers or entities of the same party. Meriam-Webster dictionary offers an alternative definition for collaboration; "to give help to an enemy who has invaded your country during a war", which implies that it may even be beneficial for competitors to collaborate (e.g., supply/logistics networks [13]).

The aforementioned definitions, however, are not precise, clear, and consistent enough, and may somehow overlap with the definitions of other related terminologies such as coordination and cooperation. A series of definitions and terminologies were provided by Nof [14], and Camarinha-Matos and Afsarmanesh [15], which help clarify the scope and breadth of collaboration and other relevant contexts. In the following, we provide the formal definitions for coordination, cooperation, and collaboration [4], and highlight their differences and interdependencies (Fig. 1):

- Coordination: Involves the use of communication and information exchange to reach mutual benefits among entities through working harmoniously.

- Cooperation: Involves, besides all aspects of coordination, a resource-sharing dimension to support goal achievement.

- Collaboration: Involves the functionalities of both coordination and cooperation, and refers to the sharing of information, resources, and responsibilities among entities to jointly plan, execute, and analyze the activities required to achieve individual and common goals. 


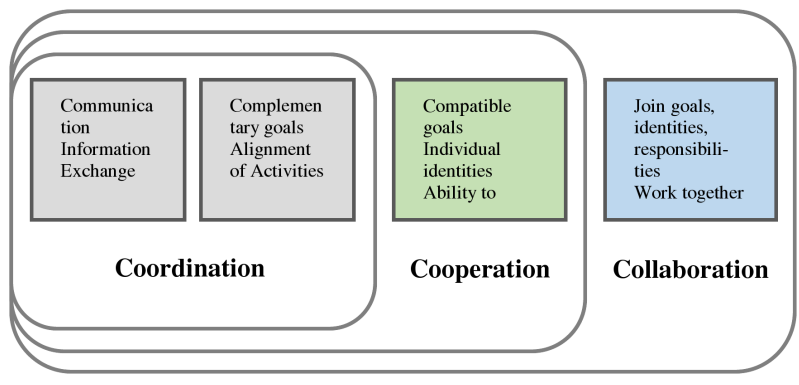

Fig. 1. Coordination, cooperation, and collaboration scopes and relationships [4].

\section{Intelligence}

Intelligence is one of those terms that we often use, in science, engineering, and everyday life, without having an exact meaning or definition for it (e.g., human intelligence; artificial intelligence; intelligent machines). Sometimes, the reason why we do not know the exact definition of a term is having no reason to know it, the term is self-descriptive/ commonsense. However, in order to formalize the intelligence and the CI, a formal definition is needed: What is intelligence? How can it be measured? What are its scope and objectives? The term "intelligence" roots in the Latin "intelligere", which means, "to comprehend or perceive". There are various definitions for intelligence, all of which somehow emphasize the capabilities of an entity to independently perceive, process, and transform specified information to specified knowledge in a certain context. Such capabilities can be broken down more into more clear concepts such as logic, reasoning, self-awareness, learning, problem solving, emotions, creativity, and so forth (Table 1).

Noticeably, all the above and similar definitions refer to intelligence as some certain ability to learn from the environment, which then enables reasoning, problem solving, and other subsequent mechanisms. This mechanism, more technically known as reinforcement learning [22], enables an agent to learn from experiments through sending actions to unknown environments and evaluating the feedback received from the environment in terms of rewards. The agent then modifies his/her/its future actions based on the rewards received over time. Following this notion, a universal intelligence measure is defined $[21,23]$ to mathematically represent the level of intelligence of agent $\omega$ as

$$
I(\omega):=\sum_{e \in E} 2^{-K(e)} R_{e}^{\omega}, \quad \forall \omega,
$$

where $K(e)$ denotes the Kolmogorov complexity of environment $e$, which is member of the set $E$ of all computable reward bounded environments, and $R_{e}^{\omega}$ is the expected sum of future rewards when agent $\omega$ interacts with environment $e$.

Table 1

Definitions of intelligence.

\begin{tabular}{|c|c|}
\hline Source & Definition \\
\hline $\begin{array}{l}\text { Cambridge } \\
\text { dictionary }\end{array}$ & $\begin{array}{l}\text { "The ability to understand and learn } \\
\text { well, and to form judgments and opin- } \\
\text { ions based on reason" }\end{array}$ \\
\hline $\begin{array}{l}\text { Meriam-Webster } \\
\text { dictionary }\end{array}$ & $\begin{array}{l}\text { "The ability to learn or understand } \\
\text { things or to deal with new or difficult } \\
\text { situations" }\end{array}$ \\
\hline Oxford dictionary & $\begin{array}{l}\text { "The ability to acquire and apply } \\
\text { knowledge and skills" }\end{array}$ \\
\hline Bingham [16] & $\begin{array}{l}\text { "We shall use the term 'intelligence' } \\
\text { to mean the ability of an organism to } \\
\text { solve new problems" }\end{array}$ \\
\hline Sternberg [17] & $\begin{array}{l}\text { "The capacity to learn or to profit by } \\
\text { experience" - W. F. Dearborn }\end{array}$ \\
\hline Wechsler [18] & $\begin{array}{l}\text { "A global concept that involves an in- } \\
\text { dividual's ability to act purposefully, } \\
\text { think rationally, and deal effectively } \\
\text { with the environment" }\end{array}$ \\
\hline Sternberg $[17]$ & $\begin{array}{l}\text { "Ability to adapt oneself adequately to } \\
\text { relatively new situations in life" }-\mathrm{R} . \\
\text { Pinter }\end{array}$ \\
\hline Sternberg $[17]$ & $\begin{array}{l}\text { "A person possesses intelligence inso- } \\
\text { far as he has learned, or can learn, to } \\
\text { adjust himself to his environment" - } \\
\text { S.S. Colvin }\end{array}$ \\
\hline Slatter [19] & $\begin{array}{l}\text { "Intelligence is part of the internal en- } \\
\text { vironment that shows through at the } \\
\text { interface between person and external } \\
\text { environment as a function of cognitive } \\
\text { task demands" - R.E. Snow }\end{array}$ \\
\hline Simonton [20] & $\begin{array}{l}\text { "There's a cluster of cognitive abilities } \\
\text { that lead to successful adaptation to a } \\
\text { wide range of environments" }\end{array}$ \\
\hline $\begin{array}{l}\text { Legg and Hutter } \\
{[21]}\end{array}$ & $\begin{array}{l}\text { "Intelligence measures an agent's abil- } \\
\text { ity to achieve goals in a wide range of } \\
\text { environments" }\end{array}$ \\
\hline
\end{tabular}

\section{Formalism}

The common feature addressed by most of the definitions of intelligence described earlier is adaptability, the ability to perceive, learn, reason, and solve new problems in dynamic environments. Now to construct the formal definition of CI, collaboration and its correspondence with the aforementioned definitions and features of intelligence must be clearly identified. Augmented collaboration, the major offspring of enhanced CI, requires automated and realtime optimization of decisions on the timing, reasoning, and location of collaboration, resource allocation, collaborative network formation and evolution, error and conflict resolution, and so forth. In other words, it calls for enhanced collaborability. In view of that, we suggest the following definition for the CI: 
CI is a measure of an agent's capability to perceive and comprehend new information, share required resources, information, and responsibilities with other peers to resolve new local and global problems in a dynamic environment. In brief, CI is a combined measure of an agent's "collaborability" and "adaptability" in dealing with emergence.

According to the above definition, and following the lessons learned from the purely theoretical universal intelligence measure (Eq. (1)) discussed in the previous section, it can be argued that

1. An agent's intelligence, specifically CI, is exponentially reduced by linear increases in the environmental complexity. This implies that complexity, regardless of any unique potentials and features that an agent may have, can drastically diminish its intelligence in dealing with its changing environment. This issue further highlights the impact of the KISS (Keep It Simple, System!) principle $[3,4]$, in this case on the CI level of agents.

2. An agent's CI is an increasing function of its expected future rewards, which can be stated in terms of cost/errors/defects/time minimization, performance/utilization/stability improvement, and so on. This implies that in an identical environment, the relative intelligence and thus the relative $C I$ ( $\mathrm{RCI}$ ) of two agents (or one agent under two different scenarios) is independent of the environmental complexity and is a function of their expected future rewards (Eq. (1)).

The universal intelligence measure described in the previous section is a generic definition, extensible to any system that receives, processes, and produces information to achieve a set of goals [21]. Hence, with slight modifications in Legg and Hutter's universal intelligence measure, we use the following formula to measure the CI of agent $\omega$

$$
\mathrm{CI}(\omega):=\sum_{n \in N} 2^{-C(n)} R_{n}^{\omega}, \quad \forall \omega,
$$

where $C(n)$ denotes the general complexity of the collaborative sub-network $n \in N$. Some strategies for collaboration, although increasing the overall CI of the entire agents/network, may diminish the CI of some particular agents compared to other alternative strategies. Hence, in a mission-oriented collabo- rative network where the global objectives are prior to the local objectives, a more precise approach is to measure the CI of the integrated agent $\Omega$ as follows

$$
\mathrm{CI}(\Omega):=\sum_{\omega \in \Omega} \sum_{n \in N} 2^{-C(n)} R_{n}^{\omega},
$$

where $\Omega=\left\{\omega_{1}, \omega_{2}, \ldots, \omega_{m}\right\}$.

As explained earlier, considering a single and identical collaborative network, the relative CI of two different agents (or one agent under two different scenarios) is sensitive merely to their total expected rewards. Therefore, the RCI (relative CI) of two arbitrary agents $\omega_{1}$ and $\omega_{2}$ can be formulated as

$$
\operatorname{RCI}\left(\omega_{1}, \omega_{2}\right):=\frac{\mathrm{CI}\left(\omega_{1}\right)}{\mathrm{CI}\left(\omega_{2}\right)}:=\frac{R_{N}^{\omega_{1}}}{R_{N}^{\omega_{2}}} .
$$

The above formula has the following simple but important implication: Considering interconnected collaborative sub-networks as a whole, where an agent may potentially interact with all of them, the RCI of any pair of agents is simply a function of their relative total expected rewards. Thus, increasing the CI of individual agents and the entire collaborative network is equivalent to increasing their collaborability and adaptability to achieve more local/global rewards from collaborative activities.

Collaboration necessitates sharing of information (supported by information and communication technologies, ICT), resources, and responsibilities, focusing on both local and global objectives of a system. The big challenge, as stated above, is how to engineer, improve, systematize, and automate collaboration processes and activities among distributed entities (e.g., people; machines; robots; software agents). Indeed, better collaboration processes are achievable through engineering augmentation of collaboration. Collaborative Control Theory (CCT) has been established and validated to optimize the intelligence and in turn, the autonomy of collaborative processes in internetworked e-Work [3]. The fundamental and emerging design principles of CCT (with ongoing discovery) are summarized in Table 2.

Next, we present three case studies on different internetworked e-Work systems, explain how their CI and RCI have been/can be improved by various CCT operators and design principles. 
Table 2

CCT principles for collaboration engineering (adapted from Nof et al. [1]).

\begin{tabular}{|c|c|c|c|}
\hline Principle* & Features & Applied concepts & Role \\
\hline $\begin{array}{l}\text { CRP "Think before you } \\
\text { act" }\end{array}$ & $\begin{array}{l}\text { - Collaboration planning \& } \\
\text { interaction } \\
\text { - Multi-agent design }\end{array}$ & $\begin{array}{l}\text { - Resource planning } \\
\text { - Agent theory }\end{array}$ & $\begin{array}{l}\text { Effective high degree of CI re- } \\
\text { quires advanced planning fol- } \\
\text { lowed by on-going, adaptive } \\
\text { control of resources }\end{array}$ \\
\hline EWP "Divide and conquer" & $\begin{array}{l}\text { - Collaboration protocol de- } \\
\text { sign } \\
\text { - Middleware protocols } \\
\text { - Parallelism } \\
\text { - Resource \& task allocation }\end{array}$ & $\begin{array}{l}\text { - Telecommunication, adap- } \\
\text { tive, and exchange protocols } \\
\text { - Client-server models } \\
\text { - Parallel/grid computing } \\
\text { - Local area networks; Inter- } \\
\text { net }\end{array}$ & $\begin{array}{l}\text { Optimally exploit the fact that } \\
\text { work in cyber work-spaces and } \\
\text { human work-spaces can and } \\
\text { must be allowed to advance } \\
\text { in parallel, and not bottle-neck } \\
\text { each other }\end{array}$ \\
\hline $\begin{array}{l}\text { ECR "Learn from mis- } \\
\text { takes" }\end{array}$ & $\begin{array}{l}\text { - Synchronization/Re- } \\
\text { synchronization } \\
\text { - Information assurance } \\
\text { - Conflict/error prevention } \\
\text { and detection }\end{array}$ & $\begin{array}{l}\text { - Agent theory } \\
\text { - Total quality management } \\
\text { - Self-healing systems }\end{array}$ & $\begin{array}{l}\text { Minimize cost of resolving con- } \\
\text { flicts among collaborating e- } \\
\text { Workers by automated e-Work } \\
\text { support systems }\end{array}$ \\
\hline CFT "Team for synergy" & $\begin{array}{l}\text { - Fault-tolerant integration } \\
\text { - Conflict resolution }\end{array}$ & $\begin{array}{l}\text { - Sensor fusion } \\
\text { - Telecommunication; } \\
\text { Co-assembly }\end{array}$ & $\begin{array}{l}\text { Fault-tolerant collaboration to } \\
\text { improve the results by a team } \\
\text { of weak agents compared to a } \\
\text { single optimized and flawless } \\
\text { agent }\end{array}$ \\
\hline AD "Be selective" & $\begin{array}{l}\text { - Enterprise integration } \\
\text { - Organizational learning }\end{array}$ & $\begin{array}{l}\text { - Network flow } \\
\text { - Enterprise computing }\end{array}$ & $\begin{array}{l}\text { Decisions } \\
\text { whether/when/why to as- } \\
\text { sociate to or dissociate from } \\
\text { a collaborative network by } \\
\text { monitoring gains/costs }\end{array}$ \\
\hline ELOCC "Trust the backup" & $\begin{aligned} \text { - } & \text { Workflow integration \& har- } \\
& \text { monization } \\
\text { - } & \text { Information sharing \& col- } \\
& \text { laboration } \\
\text { - } & \text { e-Learning/e-Training } \\
\text { - } & \text { Viability measures } \\
\text { - } & \text { e-Work scalability }\end{aligned}$ & $\begin{array}{l}\text { - Data flow; Distributed data- } \\
\text { base; Workflow protocols } \\
\text { - Virtual environments; Task } \\
\text { graphs; Network computing; } \\
\text { Internet/Intranet } \\
\text { - Learning theory; Distrib- } \\
\text { uted \& collaborative DSS } \\
\text { - Virtual manufacturing } \\
\text { - Distributed computers }\end{array}$ & $\begin{array}{l}\text { Evolutionary mechanisms of } \\
\text { interaction and organization- } \\
\text { al learning for effective ad- } \\
\text { hoc decisions improvisation, } \\
\text { on-the-spot contact creation, } \\
\text { best matching protocols pair- } \\
\text { ing planners with executors }\end{array}$ \\
\hline BIC "Follow nature" & $\begin{array}{l}\text { - Distributed optimization \& } \\
\text { control } \\
\text { - Evolution }\end{array}$ & $\begin{array}{l}\text { - Agent theory; HMS (Holonic } \\
\text { Manufacturing System); } \\
\text { Swarm intelligence; Evolu- } \\
\text { tionary algorithms } \\
\text { - Emergent networks; Neural } \\
\text { networks; Evolutionary } \\
\text { \& adaptive behaviors/ } \\
\text { patterns in nature }\end{array}$ & $\begin{array}{l}\text { Increase the intelligence and } \\
\text { thus autonomy of collabora- } \\
\text { tion mechanisms by developing } \\
\text { optimization and control solu- } \\
\text { tions inspired by the collabora- } \\
\text { tion mechanisms of nature }\end{array}$ \\
\hline
\end{tabular}

* CRP: Collaboration Requirement Planning; EWP: e-Work Parallelism; ECR: Error and Conflict Resolution; CFT: Collaborative Fault Tolerance; AD: Association-Dissociation; ELOCC: Emergent Lines of Collaboration and Command; BIC: Bio-Inspired Collaboration

\section{Internetworked e-Work Examples}

\section{HUB-CI with Collaborative Telerobots for Product Design}

Globalized markets require distributed designers to develop products collaboratively $[1,7]$. Computer Supported Collaborative Design (CSCD) is an interconnected e-Work, often among a relatively small but distributed group of participants. Collaboration between designers is usually bounded by inefficient communication about detailed design perception and knowledge. Moreover, the design team cannot build and test prototypes together, which is a critical step in product design. A HUB-CI system has been developed to improve the $\mathrm{CI}$ for $\mathrm{CSCD}$, as described in this section. 


\section{HUB-CI Collaboration Environment for Co-Design}

A CSCD e-Work network has two layers: (1) The designers as a network of humans; (2) The design tools as a network of intelligent software agents. The two networks interplay in a complex multidimensional collaboration to achieve the goal of product design. Based on the CCT, hubs of cyber resources with collaborative intelligence (HUB-CI) have been developed to enable, optimize, and augment the collaboration of humans and agent systems. HUB-CI provides intelligent tools for designers through the Internet. The CI tools are developed to manage the collaboration lifecycle in CSCD with a focus on enhancing the exchange of knowledge and insight within the design team. Figure 2 shows the Collaboration Lifecycle Management (CLM) enabled by the HUB$\mathrm{CI}$ and supported by the CCT design principles (see Table 2).

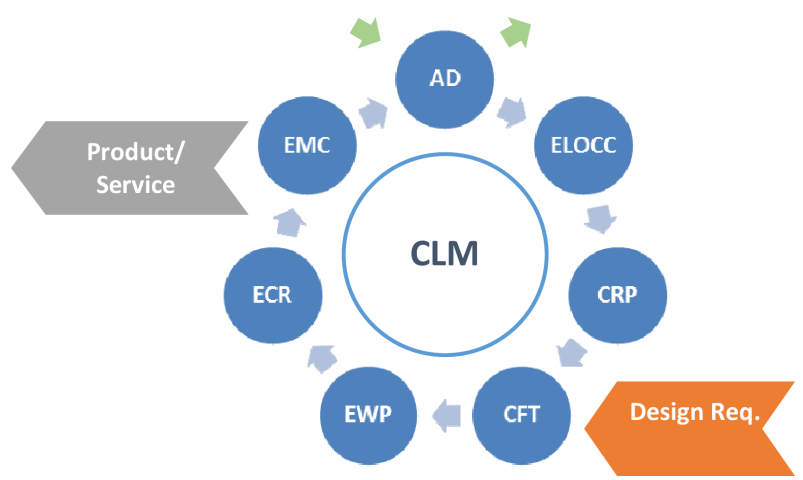

Fig. 2. CCT Tools for CLM enabled by HUB-CI [25].

\section{Collaborative Telerobotics}

Collaboration lifecycle begins at the AD node in Fig. 2, where potential participants are mapped into the design teams guided by the $\mathrm{AD}$ principle. An intelligent tool called collaborative network optimization is developed for mapping participants and design projects by minimizing the total cost of mismatch. The immediate step after forming the collaboration team is to set up the structure inside the team. The ELOCC methods with collaborative visualization techniques are used to map various participants to different interfaces by their preferences, and to build multiple lines of accountability including backups during emergent situations. When the product requirements arrive at the design team, CRP is used to allocate resources to meet the design requirements and provide knowledge by searching the knowledge base of HUB-CI. The detailed design and development workflow begins after CRP.

CFT and EWP reveal the two aspects of collaborative e-Work: Specialization and cooperation. Ex- perts and designers have different expertise. EWP empowers each individual to work with tools in parallel, so each part of the design work is handled by the right person or an expert agent. CFT indicates that in general, with intelligent protocols the teamwork of the designers can produce better products than the products developed by isolated agents. The set of design tools provided by HUB-CI can be controlled in both an individual mode and a collaborative mode to realize EWP and CFT [25]. However, the collaborative network of humans and agents is prone to errors and conflicts. ECR principle tries to detect errors as early as possible to prevent cascading failures in both cyber and physical systems [24].

The last step applies e-Measurement/Criteria (EMC), a set of e-enabled evaluation mechanisms and systems developed to examine e-Work effectiveness $[26,27]$. In CSCD, EMC determines whether the designed product is ready for testing and delivery by reaching consensus among designers and product requirements. If the design does not meet predefined requirements or additional requirements arrive, the collaboration will move into another iteration of the design process. Otherwise, the collaboration team will be restructured (using AD principle) to a new lifecycle for other projects. The dynamic teaming mechanism improves the sustainability of product design. When an agent (designer or intelligent tool) flows into another team, the knowledge she/he/it has will contribute to a different set of agents. Consequently, we will observe an increase of knowledge shared in the HUB-CI environment.

As mentioned in the previous section, engineering designers need to build prototypes. However, physical prototyping is almost impossible because of the long distance between the distributed designers. To address this challenge, telerobots are used since they enhance the reachability of humans. A telerobotenabled collaborative design project is demonstrated by Zhong et al. [25]. In this project, an electronic product is designed and prototyped by a team of distributed designers. A robotic cell is connected to a HUB-CI system, which in turn hosts the design environment for the distributed designers. The system architecture is shown in Fig. 3.

Distributed designers use a set of CI tools to draft the layout and composition of an electronic product. The tools include computer-supported software and hardware design, management of design innovation insights, and error/conflict prevention protocols. After designers reach a consensus on a prototype, an implementation request is generated to the robot. The robot renders a path plan and then assembles the design. During the robot operation, a live video 
stream captured by a camera monitoring in the telerobotics cell is transmitted back to the designers. When the circuit is assembled according designers' plan, designers can test the circuit by commanding the robot to perform inspection. In this example, the robot is controlled to turn a potentiometer and the designers diagnose the design by visual feedback. Based on the feedback, designers can verify the prototype and start another cycle of improvement, if needed.

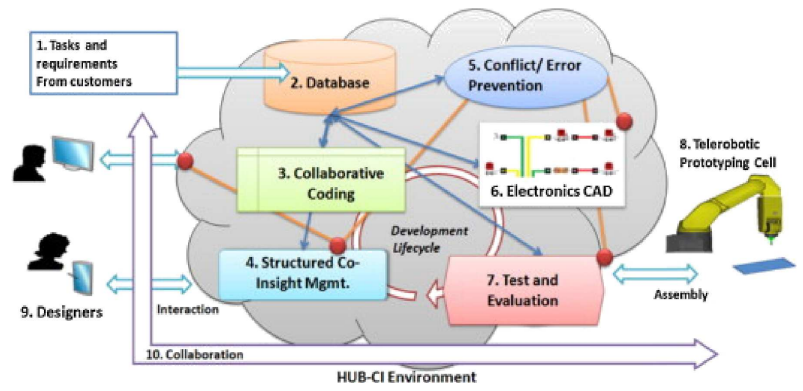

Fig. 3. HUB-CI architecture for telerobot-enabled collaborative design [25].

\section{Measured Impact of $\mathrm{HUB}-\mathrm{CI}$}

Research has shown that HUB-CI provides helpful assistance to the ideation and decision-making process from the early stages of design, the detection and prevention of errors through the design lifecycle, the drafting of product in digital and physical spaces, and the implementation and testing of prototypes. We herein measure the CI improvement in an example collaborative robotic task augmented by HUB-CI [24]. Specifically, this task requires two distributed operators to command a set of robot to accomplish a complicated repairing task. The collaborative network $(\Omega)$ is the two operator and the devices they are using. Two environments are used ( $n$ in Eq. (2)): (1) continuous control mode and (2) discrete control mode. The number of commands required to finish this task measures the complexity of each environment $(C(n)$ in Eq. $(2))$. The overall performance reward ( $R_{n}^{\omega}$ in Eq. (2)) of each collaboration is evaluated by the Time-to-Complete the task with acceptable quality (TTC; both mean $(\mu)$ and standard deviation $(\sigma))$.

$$
R_{n}^{\omega}=2^{-\mu_{T T C(n, \omega)}}+2^{-\sigma_{T T C(n, \omega)}}, \quad \forall n, \omega .
$$

In the experiment, the performance of the task supported by HUB-CI is better than the performance of the task without HUB-CI, in terms of less TTC and improved robustness. Figure 4 shows the CI of the collaborative network $(\mathrm{CI}(\Omega))$ with and without HUB-CI $\left(R_{n}^{\omega}\right.$ and $C(n)$ are normalized). The $21 \%$ improvement validates that the developed HUB-CI effectively enhance the e-Work of collaborative design.

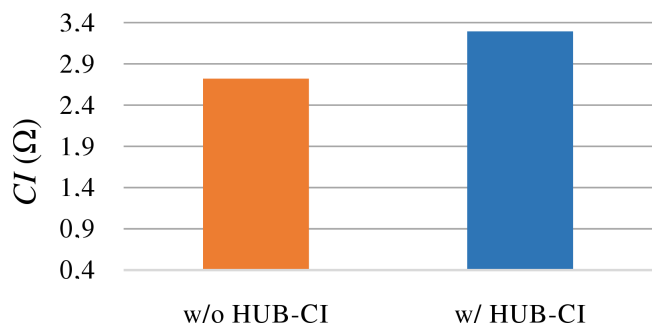

Fig. 4. The overall CI to complete a robotic task on HUB-CI

\section{CI in Resilient Supply Networks}

A supply network ( $\mathrm{SN}$ ) can be described as a collection of interconnected, autonomous agents that interact to enable the flow of tasks, physical goods, and/or data. From a topological perspective (Fig. 5), a SN can be described as the overlap of a flow network, through which agents create flow and value from inputs to outputs; and a communication network, through which agents collaborate and exchange information.

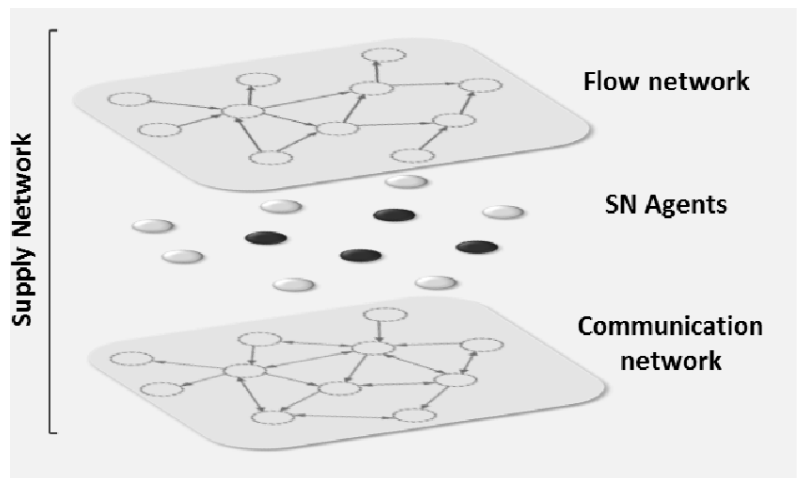

Fig. 5. Supply network topology for delivering value.

Resilience is a property of SNs and can be defined as the ability to overcome disruptions to normal operation with minimum, ideally zero, operational loss and within sustainable use of resources. According to Ponomarov and Holcomb [28] and Sterbenz et al. [29], such ability emerges from an ongoing process that comprises four phases: (1) readiness; (2) response; (3) recovery; (4) adaptation. Through these phases, the topology, operational conditions, and control protocols are continuously re-parameterized and/or re-designed. Topology plays an important role in the aforementioned process by enabling or limiting SN resilience strategies [29-31]. However, the extent to which the inherent capabilities of the SN topology are successfully leveraged by agents facing potential or actual disruptions depends on the in- 
teraction, information sharing, and collaborative creation of knowledge among agents [3].

Despite the benefits of increasing the number of SN agents that take part in collaboration efforts to enable resilience, without proper support for effective interaction and collaboration, the number of conflicts and errors, as well as the cost of interaction, increase, leading to inefficiencies and delays in decisionmaking, which may hinder efforts towards augmented resilience. The principles of CCT and the four wheels of (1) e-Work; (2) integration, coordination, and collaboration; (3) distributed decision support; and (4) active middleware [1], provide a foundation for the development of effective, efficient collaboration among agents in a SN.

In order for a set of agents to form a SN, they must exhibit some degree of interaction intelligence supported by a communication network; however, from a resilience perspective, CI is the key enabler required to achieve sustainable fault-tolerance. The significance of CI for resilience in production networks, a type of supply network in which machines, storage equipment, and humans interact to enable the flow of physical goods, is evidenced in the work of Reyes Levalle et al. [32]. The authors develop a collaborative production line control, following the principles of CCT. In this Collaborative Production Line Control (CPLC) strategy, production equipment collaborate to

1. Anticipate disruptions and their effects on the network through predictive conflict detection tools.

2. Implement preventive measures to minimize or eliminate the impact of potential disruptions by leveraging available unused capacity, parallel processing, and buffer storage, according to the network topology and capabilities.

Using a simulation model of an actual consumer packaged goods production line, the performance of
CPLC is compared to four strategies that have lower levels of CI (Fig. 6): Kanban, Base-stock, Constant Work-in-process (CONWIP), and Dynamic WIP (DWIP). Kanban and Base-stock control subdivide the production network complexity in machinebuffer pairs, however, lacking cross-pair collaboration. CONWIP and DWIP are based on centralized control, where the agent at the start of the line is responsible for decision-making. Furthermore, DWIP presents a negligible level of CI, as the decisionmaking agent is required to take into account a significantly more complex environment than its counterpart in CONWIP. Finally, CPLC presents a higher level of CI, as complexity of decisions is subdivided among processes and buffers, as in Kanban and base-stock, but with overlapping responsibilities that require higher levels of collaboration.

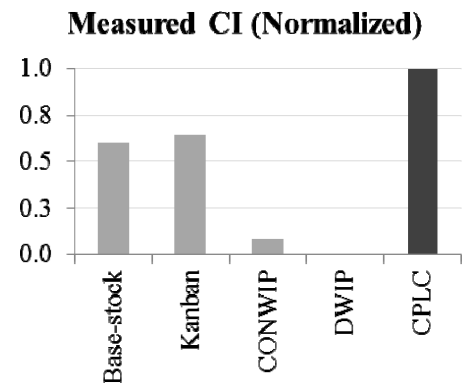

Fig. 6. CI measure for Base-stock, Kanban, CONWIP, DWIP and CPLC.

Results (Fig. 7) show with statistical significance that CPLC outperforms the alternative methods, achieving a $0.45 \%$ increase in throughput, $24 \%$ reduction in WIP, and a $43 \%$ decrease in throughput variability, when the production network is subject to random equipment failures. These results provide solid proof that protocols that apply CCT-enabled CI are capable of increasing SNs resilience.
Service level

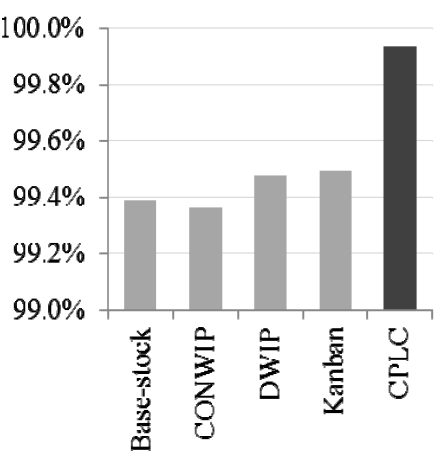

WIP (cs)

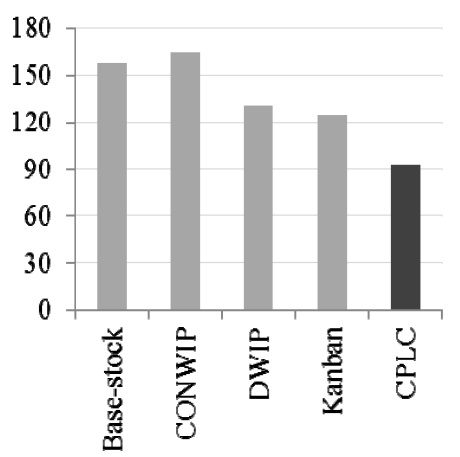

Throughput std. dev. (cs/min)

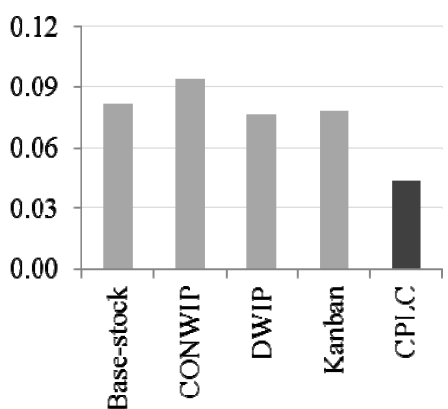

Fig. 7. CPLC vs. alternative control strategies [32]. 


\section{CI in Enterprise Collaboration}

A collaborative network of enterprises refers to a network of distributed, interconnected, and selforganizing Small-Medium-sized Enterprises (SME), which collaborate despite potential competitions to achieve individual and common benefits [4]. The transformation from classic chains to emerging networks of enterprises, i.e., having multiple enterprises in the same echelon, has enabled lateral collaboration strategies, which in turn minimize total costs, and enhance service level, resource utilization, and stability of such collaborative networks. Lateral collaboration enables enterprises with extra capacity to alleviate the overloads of enterprises with capacity shortage. The outcome will then be a network with less under- and over-loads, or more technically, less inventories and backorders/ stockout. This concept is extensible to any enterprises that process certain resources supplied from upstream in order to provide certain products/services to downstream [33]. Enterprise collaboration through Demand-Capacity Shar- ing (DCS) helps collaborating enterprise cope with the dynamic changes in demand through dynamic sharing of their demand and capacity (Fig. 8).

DCS leads to more stable flow (Fig. 9) of orders and products and lower inventories and backorders/stockout in each enterprise (i.e., the local objectives), and upholds the global market share and customer satisfaction level (i.e., the global objectives). The additional costs associated with DCS decisions and protocols, however, may diminish the effectiveness of collaboration. High frequency and quantity of collaborative activities, negotiations, information and resource sharing, physical distribution of stocks, and other business operation require considerable resources. These negative impacts may be intensified, if the enterprises are not properly matched to the customers with respect to the level of correspondence between the demand and capacity levels, which in turn leads to excessive rates/costs of DCS among enterprises. This is a clear example for "blind collaboration", which needs to be augmented by CCT-enabled CI.

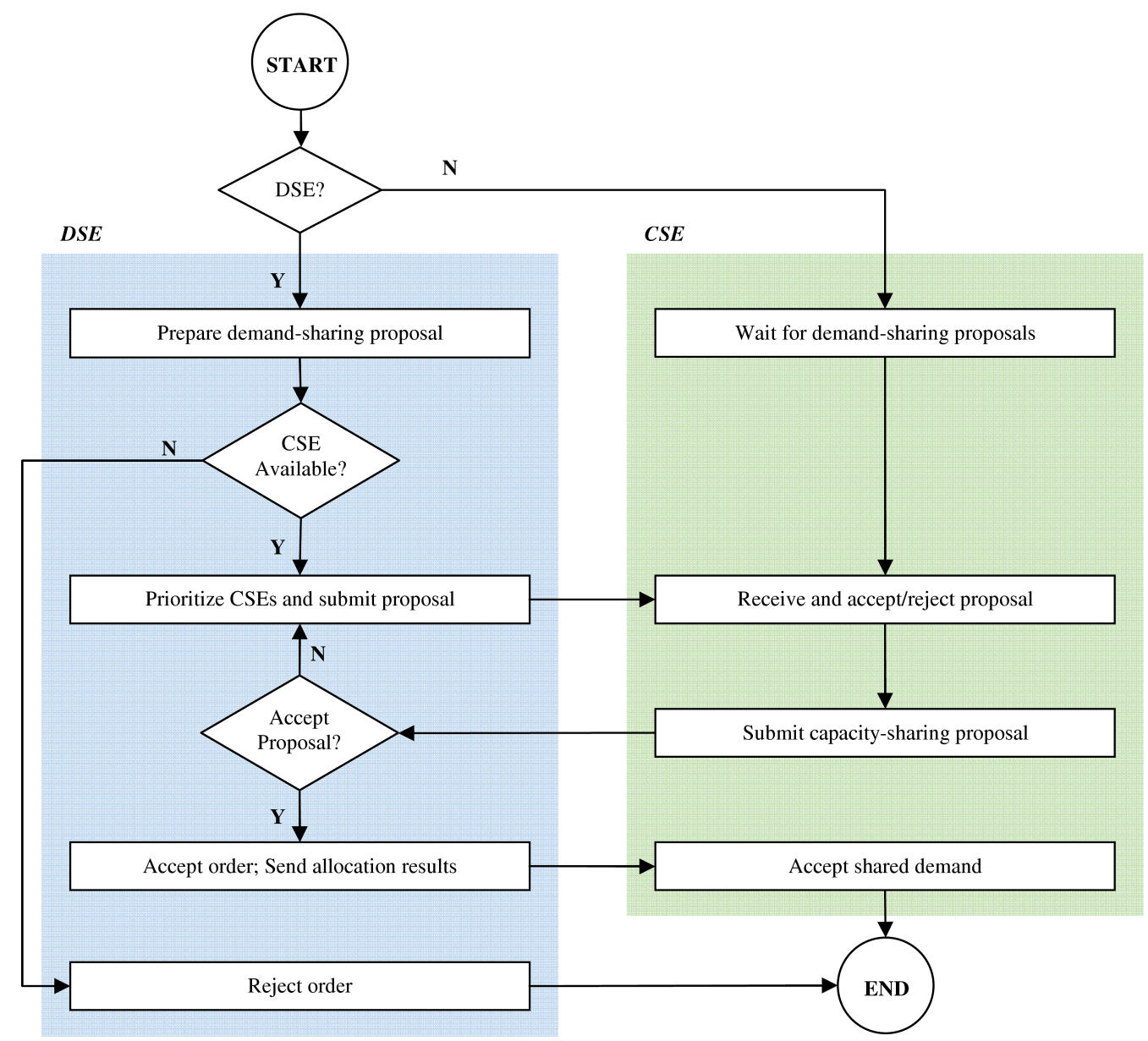

Fig. 8. Demand and capacity sharing logic [DSE: Demand-Sharing Enterprise; CSE: Capacity-Sharing Enterprise]. 


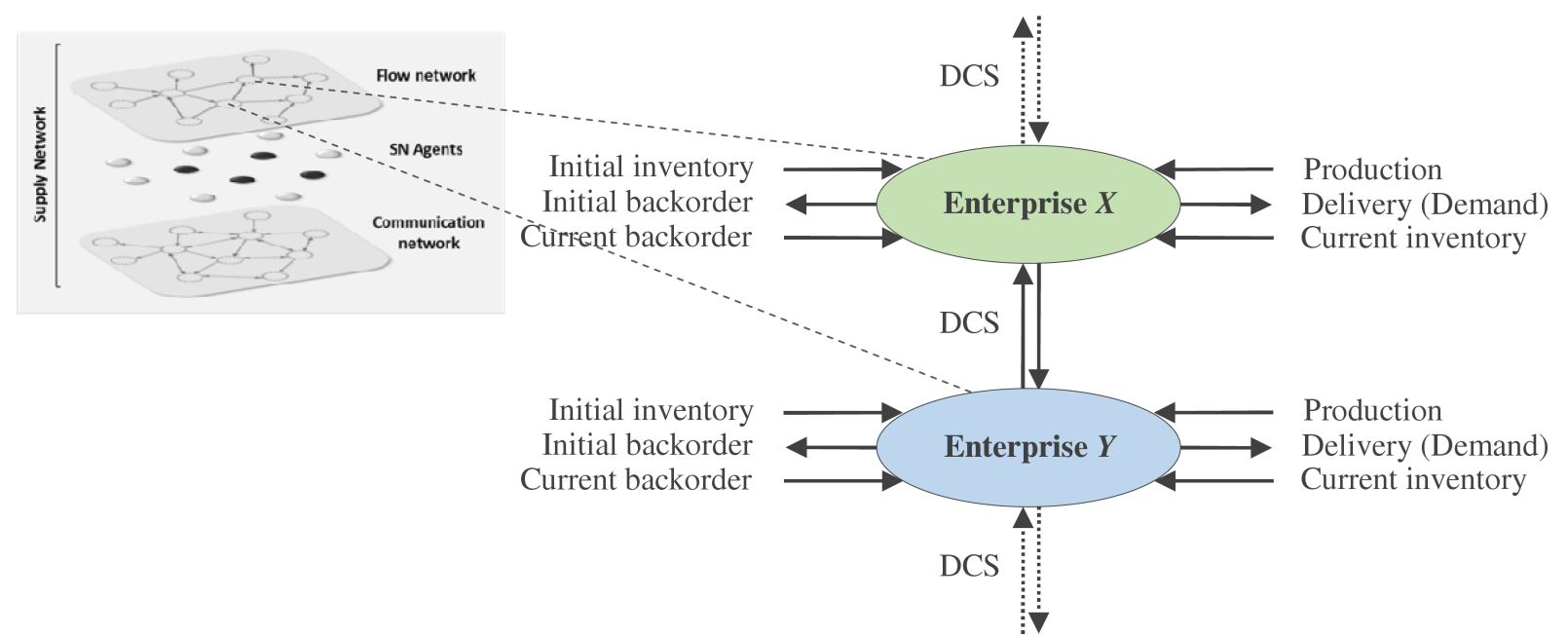

Fig. 9. A generic model of product/service flow between two collaborative enterprises (adapted from Moghaddam and Nof [33]).

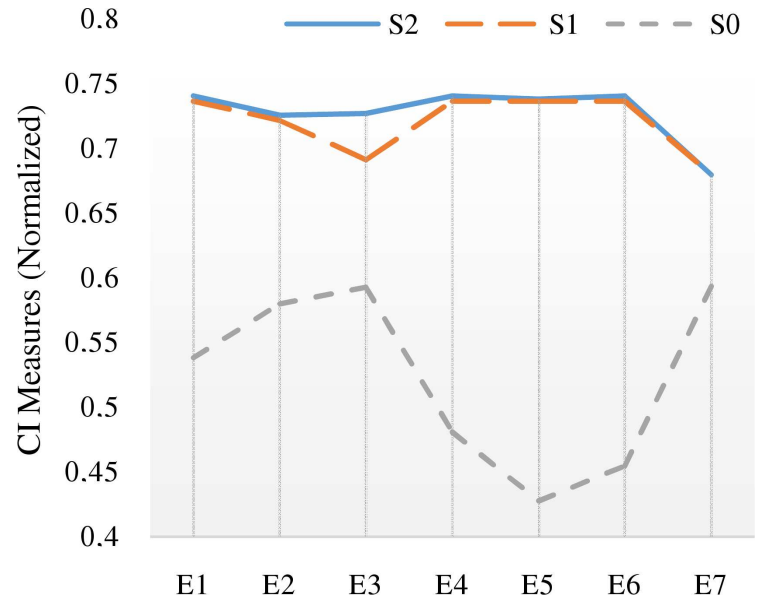

Fig. 10. The CI values (approximated and normalized) for each enterprise under different scenarios (EX: Enterprise $\mathrm{X}$ )

Best-Matching Protocol (BMP) is an effective enabler of $\mathrm{CI}$ in both lateral and vertical enterprise collaboration, through dynamically matching of (1) demand- and capacity-sharing enterprises, and (2) enterprises and customers, respectively. In our experiments, a collaborative network composed of 7 enterprises and 21 customers is simulated over three different periods [33]. Three different scenarios are involved, including no-collaboration $\left(S_{0}\right)$, CI-enabled lateral collaboration $\left(S_{1}\right)$, and CI-enabled lateral and vertical collaboration $\left(S_{2}\right)$. Since the complexity of the collaborative network and sub-networks cannot be explicitly defined, we skip the complexity calculations, and focus on the overall rewards individual enterprises under each scenarios, as an indicator of the CI. In the case under study, the agents (i.e., enterprises) are rewarded in terms of resource utilization, service level, stability, and total cost minimization (see [33] for details). The overall reward can be calculated as the weighted sum of the normalized values of each indicator, which are weighted equally in our case. Figure 10 shows the integrated RCI values of the enterprises over three periods. Our detailed results indicated that intelligent collaboration through BMP drastically improves costs and service level, while upholding the resource utilization and stability provided by random or non-optimal collaboration mechanisms.

\section{Conclusions}

The Internet and Internet-enabled applications have transformed the way we collaborate or design collaboration; nevertheless, abundant benefits are yet to come with increasing levels of CI: By people adding intelligent methods, algorithms and protocols to help collaboration over cyber-physical networks. In this article, we defined and formulated the CI, and demonstrated through three case studies in different areas of collaboration in internetworked eWork how with improved CI among the agents better values can be created. It is observed consistently from these studies that the CI development has significant impact on improving work efficiency, collaborative network robustness and stability, service level, and resource utilization: All of which are common goals the participating agents are designed to achieve. Table 3 summarizes the measured impacts on internetworked e-Work based on the CI research presented in this article. 
Table 3

Measured impacts of CI on Internetworked e-Work.

\begin{tabular}{l|l|l|l}
\hline e-Criteria & Case 1: Collaborative design & Case 2: SN control & Case 3: DCS \\
\hline Efficiency & $\begin{array}{l}\text { Less time to complete design } \\
\text { tasks }\end{array}$ & $\begin{array}{l}\text { Increased throughput and re- } \\
\text { duced WIP }\end{array}$ & Improved resource utilization \\
\hline $\begin{array}{l}\text { Stability; service level; } \\
\text { effectiveness }\end{array}$ & $\begin{array}{l}\text { Improved design robustness, } \\
\text { quality }\end{array}$ & $\begin{array}{l}\text { Decreased throughput variabli- } \\
\text { ty }\end{array}$ & Improved network stability \\
\hline Collaboration cost & $\begin{array}{l}\text { Errors removed at early stages } \\
\text { of design }\end{array}$ & $\begin{array}{l}\text { Minimized impact of disrup- } \\
\text { tions }\end{array}$ & Reduced cost of mismatch \\
\hline
\end{tabular}

While it is intuitive that higher levels of CI lead to better performance, as indicated, we are still struggling with a two-fold challenge: (1) Find the best ways to create, foster, and sustain the CI throughout the lifecycle of particular e-Activities; (2) Simplify and optimize, not maximize, the level of CI; it has been proven that optimal performance is usually achieved with optimal and selective levels of CI.

Following the trends of discovering CI-based methodologies to improve e-Work, future research will seek to discover more about collaboration and interaction science, and provide adaptable solutions with the evolving developments in cyber technology. Some areas that are currently attracting our research attention include collaboration in nano-scale systems (each agent is small with limited capability and difficult to control, but the collection of agents, e.g., agent swarms, is relatively huge and versatile); transscale systems (CI methodology has to overcome the diversity of agents at different scales); bio-inspired collaborative control (animal crowds are good at strengthening their sustainability through collective behaviors; the collaboration mechanisms between individuals are applicable for engineered e-Work systems), and more. Two specific questions are open to further investigation:

1. How can we efficiently transfer the knowledge and capabilities of collaboration from skilled agents (e.g., people, experts) to novice agents (e.g., automated units)?

2. How can CI be applied to counterbalance the immediate, short-term goals (e.g., profits) with longterm goals (e.g., survival, sustainability of collaborative networks)?

Research reported in this article has been developed at the PRISM (Production, Robotics, and Integration Software for Manufacturing and Management) Center at Purdue University with NSF, Indiana 21st Century Fund for Science $\& 3$ Technology, and industry support.

\section{References}

[1] Nof S.Y., Ceroni J., Jeong W., Moghaddam M., Revolutionizing Collaboration through e-Work,
e-Business, and e-Service, Springer Series in ACES, Automation, Collaboration, \& E-Service, in press, 2015.

[2] Nowak M.A., Five rules for the evolution of cooperation, Science, 8, 314 (5805), 1560-3, 2006.

[3] Nof S.Y., Collaborative control theory for e-Work, eProduction, and e-Service, Annual Reviews in Control, 31, 2, 281-292, 2007.

[4] Nof S.Y., Design of effective e-Work: review of models, tools, and emerging challenges, Production Planning \& Control, 14, 8, 681-703, 2003.

[5] Nof S.Y., Morel G., Monostori L., Molina A., Filip F., From Plant and Logistics Control to MultiEnterprise Collaboration, Annual Reviews in Control, 30, 55-68, 2006.

[6] Chituc C.M., Nof S.Y., The join/leave/remain $(J L R)$ decision in collaborative networked organizations, Computers and Industrial Engineering, 53, 1, 173-195, 2007.

[7] Devadasan P., Zhong H., Nof S.Y., Collaborative intelligence in knowledge based service planning, Expert Systems with Applications, 40, 17, 6778-6787, 2013.

[8] Elrod P.D., Tippet D.D., An empirical study of the relationship between team performance and team maturity, IEEE Engineering Management Review, $36,1,52,2008$.

[9] Zhu X., Goldberg A.B., Introduction to semisupervised learning, Morgan \& Claypool, 2009.

[10] Pinto M.B., Pinto J.K., Project team communication and cross-functional cooperation in new program development, Journal of Product Innovation Management, 7, 200-212, 1990.

[11] Nguyen N.T., Inconsistency of knowledge and collective intelligence, Cybernetics and Systems, 39, 6, 542-562, 2008.

[12] Devadasan P., Collaborative intelligence measure for knowledge based service industry, MS Thesis, School of Industrial Engineering, Purdue University, 2011.

[13] Zhao X., Atkins D., Transshipment between competing retailers, IIE Transactions, 41, 8, 665-676, 2009. 
[14] Nof S.Y., Information and Collaboration Models of Integration, Kluwer, Dordrecht, 1994.

[15] Camarinha-Matos L.M., Afsarmanesh H., Collaborative networks: Value creation in a knowledge society, Proc. PROLAMAT 2006, IFIP Int. Conf. Knowl. Enterp. - New Challenges, Shanghai, 2006.

[16] Bingham W.V., Aptitudes and aptitude testing, New York: Harper \& Brothers, 1937.

[17] Sternberg R.J. (Ed.), Handbook of intelligence, Cambridge University Press, 2000.

[18] Wechsler D., The measurement and appraisal of adult intelligence (4 ed.), Baltimore, Williams \& Wilkinds, 1958.

[19] Slatter J., Assessment of children: Cognitive applications (4th ed.), San Diego, Jermone M. Satler Publisher Inc., 2001.

[20] Simonton D.K., An interview with Dr. Simonton, In Human intelligence: Historical influences, current controversies, teaching resources, J.A. Plucker [Ed.], 2003.

[21] Legg S., Hutter M., Universal intelligence: A definition of machine intelligence, Minds and Machines, 17, 4, 391-444, 2007.

[22] Sutton R., Barto A., Reinforcement learning: An introduction, MIT Press, Cambridge, 1998.

[23] Legg S., Vennes J., An Approximation of the Universal Intelligence Measure. Algorithmic Probability and Friends, Bayesian Prediction and Artificial Intelligence Lecture Notes in Computer Science, 7070, 236-249, 2013.

[24] Zhong H., Wachs J.P., Nof S.Y., A collaborative telerobotics network framework with hand gesture interface and conflict prevention, International Journal of Production Research, 51, 15, 4443-4463, 2013.

[25] Zhong H., Wachs J.P., Nof S.Y., Telerobot-enabled HUB-CI model for collaborative lifecycle manage- ment of design and prototyping, Computers in Industry, 65, 4, 550-562, 2014.

[26] Huang C.-Y., Nof S.Y., Evaluation of agent-based manufacturing systems based on a parallel simulator, Computers \& Industrial Engineering, 43, 3, 529-52, 2002

[27] Jeong W., Nof S.Y., Performance evaluation of wireless sensor network protocols for industrial applications, Journal of Intelligent Manufacturing, 19, 335-345, 2008.

[28] Ponomarov S.Y., Holcomb M.C., Understanding the concept of supply chain resilience, International Journal of Logistics Management, 20, 1, 124-143, 2009 .

[29] Sterbenz J.P.G., Cetinkaya E.K., Hameed M.A., Jabbar A., Qian S., Rohrer J.P., Evaluation of network resilience, survivability, and disruption tolerance: analysis, topology generation, simulation, and experimentation, Telecommunication Systems, 52, 2, 1-32, 2011.

[30] Nair A., Vidal J.M., Supply network topology and robustness against disruptions - An investigation using multi-agent model, International Journal of Production Research, 49, 5, 1391-1404, 2011.

[31] Adenso-Diaz B., Mena C., Garcia-Carbajal S., Liechty M., The impact of supply network characteristics on reliability, Supply Chain Management, 17, 3, 263-276, 2012.

[32] Reyes Levalle R., Scavarda M., Nof S.Y., Collaborative production line control: Minimisation of throughput variability and WIP, International Journal of Production Research, 51, 23-24, 7289-7307, 2013.

[33] Moghaddam M., Nof S.Y., Combined demand and capacity sharing with best matching decisions in enterprise collaboration, International Journal of Production Economics, 148, 93-109, 2014. 